\title{
IMPLEMENTASI LEAN MANUFACTURING UNTUK MENINGKATKAN OUTPUT PRODUKSI INTRA VENOUS CATHETER DI PT. NIPRO INDONESIA JAYA
}

\author{
Edo Kurniawan, Umi Marfuah \\ Program Studi Teknik Industri \\ Universitas Muhammadiyah Jakarta \\ dhoe.kurniawan@gmail.com, umi.marfuah@ftumj.ac.id
}

\begin{abstract}
Abstrak
PT. Nipro Indonesia Jaya (NIJ) sebagai salah satu perusahaan manufaktur yang bergerak di bidang Alat Kesehatan tidak terlepas dari masalah yang berkaitan dengan pencapaian output produksi yaitu proses perakitan Intra Venous Catheter (IV Cath). Rata-rata pencapaian output produksi IV Cath adalah sebesar $94 \%$ dari target perusahan yaitu 100\%. Tidak tercapainya output produksi pada setiap bulan akan menyebabkan pengiriman produk ke customer akan terganggu karena proses produksi menggunakan sistem made to order. Dari informasi yang didapatkan dari dept. produksi, dalam proses perakitan IV Cath saat ini masih sering ditemukan pemborosan atau waste. Dengan metode Lean Manufacturing penulis berharap terjadi peningkatan output produksi produk IV Cath. Pemborosan yang terjadi diidentifikasi dengan seven waste. Kondisi perusahaan digambarkan dengan Big Picture Mapping. Analisa dilakukan dengan Value Stream Analysis Tools (VALSAT) untuk kemudian diketahui akar penyebabnya. Dari hasil pengolahan data didapatkan nilai rata-rata tertinggi untuk pemborosan yaitu; transportation (54.8\%). waiting (23.0\%), motion (18.3\%) dan inventory (4.0\%). Nilai rata-rata dikalikan dengan factor pengali pada VALSAT, sehingga didapatkan VALSAT yang digunakan adalah Process Activity Mapping (110.67). Waktu lead time sebelum perbaikan adalah sebesar 8,992 detik dan setelah perbaikan menjadi 6,902 detik. Output produksi meningkat sebesar $10 \%$ dari 292,768 pcs/bulan menjadi 321,333 pcs/bulan.
\end{abstract}

Kata kunci: Waste, Output Produksi, Lean, Process Activity Mapping

\begin{abstract}
PT. Nipro Indonesia Jaya (NIJ) is company who engaged in Medical Device manufacturing. PT NIJ can't be separated from a problem regarding with achievement of production. Based on data of production dept, the process which have a problem about achievement of production output is process of Intra Venous Catheter (IV Cath) assembly. Average of production output achievement is $94 \%$ from company target is $100 \%$. This problem can make the delivery product to customer will disturb due production process use made to order system. Based on information from production dept, on the process still found waste. With Lean Manufacturing method expect will increase production output of IV Cath product. Waste which occur identified by seven waste. Company condition described by Big Picture Mapping. Analyze by Value Steram Mapping Tools (VALSAT) then knows of root cause. Based on data processed get the highest of average score for waste are transportation (54.8\%). waiting (23.0\%), motion (18.3\%) dan inventory (4.0\%). Average score multiplied with multiplier factor on VALSAT, then get the VALSAT which used is Process Activity Mapping (110.67). Lead time before improvement is 8,992 seconds and after improvement is 6,902 seconds. Production output increased as $10 \%$ from 292,768 pcs/month to be 321,333 pcs/month.
\end{abstract}

Key words: Waste, Production Output, Lean, Process Activity Mapping

\section{PENDAHULUAN}

PT. Nipro Indonesia Jaya (NIJ) merupakan salah satu perusahaan manufaktur yang bergerak di bidang Alat Kesehatan/Medical Devices. PT. NIJ memproduksi berbagai alat kesehatan seperti ; Syringe, IV Cath, IF Set, AVF dan BTS dengan merek dagang NIPRO yang dipasarkan secara lokal ataupun ekspor. PT. NIJ berusaha untuk terus menerus memperkuat posisinya melalui perbaikan secara berkelanjutan (continuos improvement) terhadap setiap departemen serta proses didalamnya, agar dapat merespon perubahan pasar dengan cepat dan bertahan untuk mencapai tujuan yang diinginkan. 
PT. NIJ tidak terlepas dari masalah yang berkaitan dengan pencapaian output produksi. Menurut data departemen produksi, proses yang yang sering mengalami masalah dalam pencapaian output produksi adalah proses perakitan Intra Venous Catheter (IV Cath). Produk IV Cath adalah produk alat kesehatan yang digunakan untuk keperluan infus. Tidak tercapainya output produksi pada setiap bulan akan menyebabkan pengiriman produk ke customer akan terganggu karena proses produksi menggunakan sistem made to order. Rata-rata pencapaian output produksi IV Cath adalah sebesar 94\% dari target perusahan yaitu $100 \%$. Data tersebut menunjukkan bahwa ada masalah yang terjadi pada proses tersebut yang dapat ditimbulkan oleh berbagai faktor penyebab yang harus diperbaiki agar pencapaian output produksi dapat sesuai target. Berikut ini data persentase output produksi yang menunjukan produk IV Cath paling rendah diantara produk yang lain yang diproduksi PT NIJ dari bulan Oktober 2016 Maret 2017 :

Tabel 1. Persentase Output Produksi PT Nipro Indonesia Jaya Periode Oktober 2016 Maret 2017 (Sumber : PT. NIJ)

\begin{tabular}{|l|c|c|c|c|c|c|}
\hline \multicolumn{1}{|c|}{ Bulan } & BTS & Syringe & $\begin{array}{c}\text { Insulin } \\
\text { Syringe }\end{array}$ & IV Cath & AVF & IF Set \\
\hline Oktober 2016 & $100 \%$ & $101 \%$ & $98 \%$ & $92 \%$ & $100 \%$ & $98 \%$ \\
\hline November 2016 & $99 \%$ & $100 \%$ & $99 \%$ & $93 \%$ & $102 \%$ & $100 \%$ \\
\hline Desember 2016 & $101 \%$ & $98 \%$ & $100 \%$ & $93 \%$ & $102 \%$ & $99 \%$ \\
\hline Januari 2017 & $100 \%$ & $100 \%$ & $99 \%$ & $93 \%$ & $100 \%$ & $100 \%$ \\
\hline Februari 2017 & $98 \%$ & $100 \%$ & $100 \%$ & $96 \%$ & $99 \%$ & $97 \%$ \\
\hline Maret 2017 & $100 \%$ & $99 \%$ & $98 \%$ & $96 \%$ & $103 \%$ & $96 \%$ \\
\hline Rata-rata & $100 \%$ & $100 \%$ & $99 \%$ & $94 \%$ & $101 \%$ & $98 \%$ \\
\hline $\begin{array}{l}\text { Target Perusahaan } \\
\text { KPI) }\end{array}$ & $100 \%$ & $100 \%$ & $100 \%$ & $100 \%$ & $100 \%$ & $100 \%$ \\
\hline
\end{tabular}

Dari tabel diatas menyatakan proses IV Cath persentase output produksinya terendah. Dari informasi yang didapatkan dari dept. produksi, dalam proses perakitan IV Cath saat ini masih sering ditemukan pemborosan atau waste yang disebabkan oleh beberapa hal. Adapun pemborosan atau waste yang sering ditemukan adalah :

a. Transportation, terjadi pada saat pengiriman produk dari satu proses ke proses selanjutnya.

b. Motion, gerakan operator mengambil material.

c. Waiting, terjadi ketika operator menunggu mesin bekerja.

\section{LANDASAN TEORI}

Lean pertama kali diperkenalkan oleh Toyota dan dikenal dengan Toyota Production System (Liker, 2004). Sistem Produksi Toyota yang di gambarkan oleh Taiichi Ohno pendirinya yaitu bagaimana perusahaan melihat kedalam time line dari saat pelanggan memberikan pesanan sampai titik dimana perusahaan peroleh uang tunai dan memperpendek time line dengan menghilangkan non value added wastes (Liker, 2004).

Tujuan dari lean manufacturing adalah untuk mengurangi waste dalam tenaga kerja dan persediaan, time to market tepat waktu, dan mengelola persediaan untuk produksi yang sangat responsif terhadap permintaan pelanggan sambil menghasilkan produk berkualitas dengan cara yang paling efisien dan ekonomis. Lean manufacturing berfokus pada efisiensi, bertujuan untuk menghasilkan produk dan jasa pada biaya terendah dan dalam waktu sesingkat- singkatnya. Konsep lean thinking berasal dari toyota production system (TPS) yang menentukan nilai setiap proses dengan cara membedakan value added activities dari non value added activities dan menghilangkan waste sehingga setiap langkah memberikan nilai tambah didalam proses.

Big picture mapping merupakan tool yang digunakan untuk menggambarkan sistem secara keseluruhan dan value stream yang ada didalamnya. Tool ini juga dapat digunakan untuk 
mengidentifikasi dimana terdapat pemborosan, serta mengetahui keterkaitan antara aliran informasi dan aliran material (Hines, 2000).

Value Stream Analysis Tools (VALSAT) merupakan suatu tools yang digunakan untuk memetakan value stream secara detail waste pada aliran nilai yang fokus pada value adding process, terdapat 7 (tujuh) detail mapping tools yang bermanfaat untuk memetakan waste. Masing - masing tools mempunyai bobot low, medium dan high sesuai ketentuan peringkatnya dan menunjukkan skor yang kemudian dapat diketahui mapping mana yang mengindikasikan sedikit atau besarnya pengaruh pemborosan. VALSAT merupakan tool yang dikembangkan untuk mempermudah pemahaman terhadap value stream, mempermudah untuk membuat perbaikan berkenaan dengan waste. VALSAT yang juga merupakan sebuah pendekatan yang digunakan dengan melakukan pembobotan waste - waste, kemudian dari pembobotan tersebut dilakukan pemilihan terhadap tool dengan menggunakan matrik (Hines 2004).

Tabel 2. Value Stream Analysis Tools (Sumber: Hines (2004)

\begin{tabular}{|l|c|c|c|c|c|c|c|}
\hline \multirow{1}{*}{ Waste } & $\begin{array}{c}\text { Process } \\
\text { Activity } \\
\text { Mapping }\end{array}$ & $\begin{array}{c}\text { Supply } \\
\text { Chain } \\
\text { Matrix }\end{array}$ & $\begin{array}{c}\text { Production } \\
\text { Variety } \\
\text { Mapping }\end{array}$ & $\begin{array}{c}\text { Quality } \\
\text { Filter } \\
\text { Mapping }\end{array}$ & $\begin{array}{c}\text { Demand } \\
\text { Application }\end{array}$ & $\begin{array}{c}\text { Decision } \\
\text { Point } \\
\text { Analysis }\end{array}$ & $\begin{array}{c}\text { Physical } \\
\text { Structure }\end{array}$ \\
\hline Over Production & $L$ & $M$ & & $L$ & $M$ & $M$ & \\
\hline Waiting & $H$ & $H$ & $L$ & & $M$ & $M$ & \\
\hline Transportation & $H$ & & & & & & L \\
\hline Inventory & $H$ & & $M$ & $L$ & & $L$ & \\
\hline Motion & $M$ & $H$ & $M$ & & $H$ & $M$ & $L$ \\
\hline Defect & $H$ & $L$ & & $H$ & & & \\
\hline Excess Processing & $L$ & & & & $H$ & & \\
\hline
\end{tabular}

Keterangan :

$$
\begin{array}{ll}
-\mathrm{H}(\text { High Correlation }) & : \text { faktor pengali }=9 \\
-\mathrm{M}(\text { Medium Correlation }) & : \text { faktor pengali }=3 \\
-\mathrm{L}(\text { Low Correlation }) & : \text { faktor pengali }=1
\end{array}
$$

\section{METODELOGI PENELITIAN}

Pada bab ini membahas mengenai tahap penyusunan dan penyelesaian suatu penelitian, dari awal penelitian sampai selesai penelitian. Seperti membuat latar belakang masalah, perumusan masalah, menetapkan tujuan penelitian, pembatasan masalah, cara pengumpulan data, analisis sampai menarik kesimpulan. Semua tercakup dalam kerangka pemecahan masalah.

\section{HASIL DAN PEMBAHASAN}

Tabel 3. Data Produksi Perakitan IV Cath bulan Oktober 2016 - Maret 2017 (Sumber : PT. NIJ)

\begin{tabular}{|c|c|c|c|}
\hline \multirow{2}{*}{ Bulan } & $\begin{array}{c}\text { Output } \\
\text { Produksi } \\
(\mathbf{p c s})\end{array}$ & $\begin{array}{c}\text { Target Output } \\
(\mathbf{p c s})\end{array}$ & \% Pencapaian \\
\hline Oktober 2016 & 294,588 & 320,000 & $92 \%$ \\
\hline November 2016 & 289,251 & 310,000 & $93 \%$ \\
\hline December 2016 & 280,121 & 300,000 & $93 \%$ \\
\hline Januari 2017 & 297,512 & 320,000 & $93 \%$ \\
\hline Februari 2017 & 296,983 & 310,000 & $96 \%$ \\
\hline Maret 2017 & 298,154 & 310,000 & $96 \%$ \\
\hline
\end{tabular}

Dari tabel 3. diketahui bahwa output produksi IV Cath dari bulan Oktober 2016 s/d Maret 2017 selalu tidak mencapai target yang telah ditetapkan. 


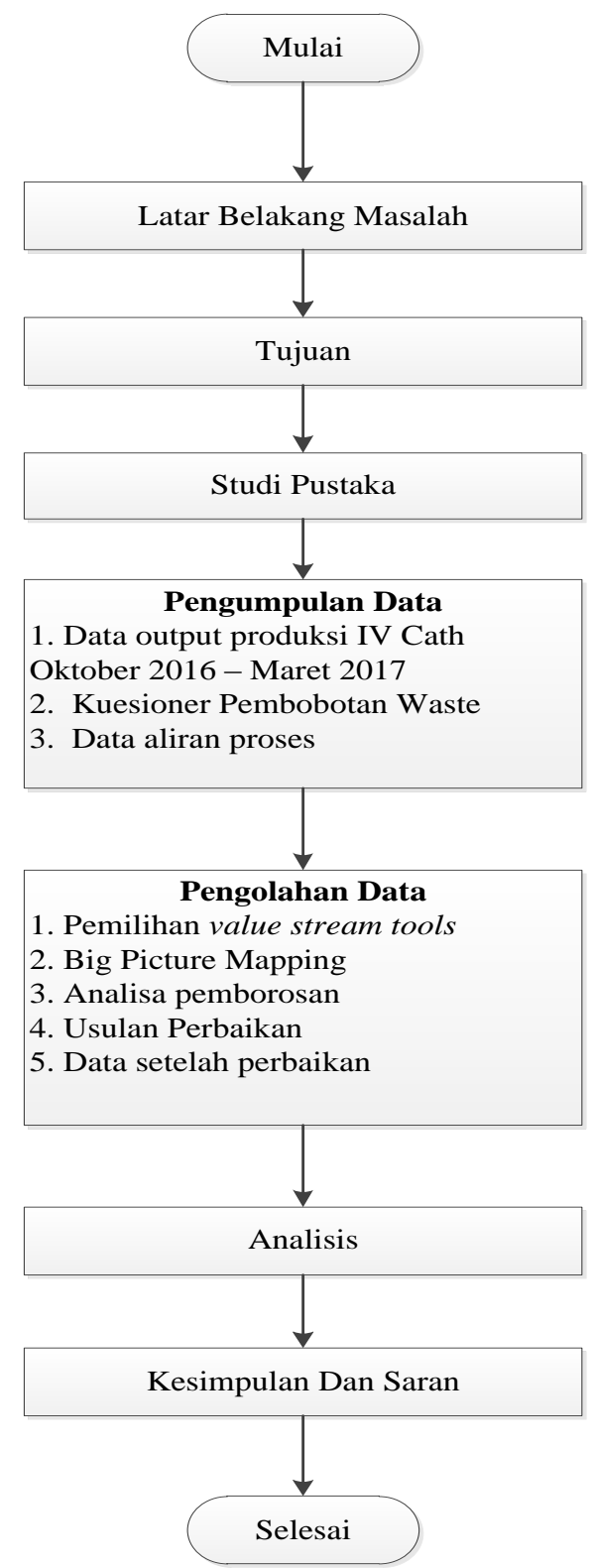

Gambar 1. Flow Chart Metodologi Penelitian (Sumber : Hasil Penelitian)

\section{Pemilihan Value Stream Analysis Tools (VALSAT)}

Penelitian dilakukan dengan menyebarkan kuesioner kepada 5 orang karyawan produksi IV Cath sebagai responden untuk mengetahui bobot waste pada masing-masing stasiun kerja. 
Tabel 4. Data Rekapitulasi Kuesioner Pembobotan Pemborosan (Sumber : Hasil Perhitungan)

\begin{tabular}{|c|c|c|c|c|c|c|c|c|c|}
\hline No & $\begin{array}{c}\text { Stasiun } \\
\text { Kerja }\end{array}$ & 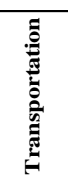 & 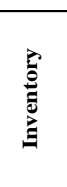 & 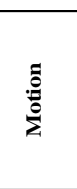 & 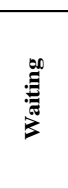 & 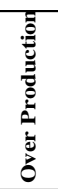 & 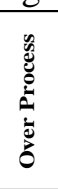 & 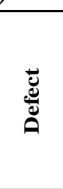 & हี \\
\hline 1 & $\mathrm{~A}$ & 1 & 3 & 0 & 0 & 0 & 0 & 0 & 4 \\
\hline 2 & B & 0 & 0 & 0 & 0 & 0 & 0 & 0 & 0 \\
\hline 3 & $\mathrm{C}$ & 17 & 0 & 19 & 0 & 0 & 0 & 0 & 36 \\
\hline 4 & $\mathrm{D}$ & 15 & 0 & 4 & 20 & 0 & 0 & 0 & 39 \\
\hline 5 & E & 0 & 2 & 0 & 0 & 0 & 0 & 0 & 2 \\
\hline 6 & $\mathrm{~F}$ & 15 & 0 & 0 & 0 & 0 & 0 & 0 & 15 \\
\hline 7 & G & 0 & 0 & 0 & 0 & 0 & 0 & 0 & 0 \\
\hline 8 & $\mathrm{H}$ & 5 & 0 & 0 & 0 & 0 & 0 & 0 & 5 \\
\hline 9 & I & 16 & 0 & 0 & 9 & 0 & 0 & 0 & 25 \\
\hline \multicolumn{2}{|c|}{ TOTAL } & 69 & 5 & 23 & 29 & 0 & 0 & 0 & 126 \\
\hline \multicolumn{2}{|c|}{ Average } & 7.67 & 0.56 & 2.56 & 3.22 & 0.00 & 0.00 & 0.00 & 14 \\
\hline \multicolumn{2}{|c|}{ Persentase } & $54.8 \%$ & $4.0 \%$ & $18.3 \%$ & $23.0 \%$ & $0.0 \%$ & $0.0 \%$ & $0.0 \%$ & $100.0 \%$ \\
\hline
\end{tabular}

Dari hasil rekapitulasi didapatkan bahwa stasiun kerja C, stasiun kerja D, stasiun kerja F \& stasiun kerja I yang memiliki skor waste tertinggi. Adapun 3 (tiga) nilai waste tertinggi adalah :

1. Transportation, dengan nilai rata-rata sebesar 7.67

2. Waiting, dengan nilai rata-rata sebesar 3.22

3. Motion, dengan nilai rata-rata sebesar 2.56

Setelah diketahui nilai rata-rata masing-masing waste maka dilakukan perhitungan untuk menentukan Value Stream Analysis Tools (VALSAT) yang akan digunakan dengan menggunakan tabel VALSAT sebagai berikut :

Tabel 5. Hasil Perhitungan Pemilihan VALSAT (Sumber : Hasil Perhitungan)

\begin{tabular}{|c|c|c|c|c|c|c|c|}
\hline Waste & $\begin{array}{c}\text { Process } \\
\text { Activity } \\
\text { Mapping }\end{array}$ & $\begin{array}{c}\text { Supply } \\
\text { Chain } \\
\text { Matrix }\end{array}$ & $\begin{array}{c}\text { Production } \\
\text { Variety } \\
\text { Mapping }\end{array}$ & $\begin{array}{c}\text { Quality } \\
\text { Filter } \\
\text { Mapping }\end{array}$ & $\begin{array}{c}\text { Demand } \\
\text { Application }\end{array}$ & $\begin{array}{c}\text { Decision } \\
\text { Point } \\
\text { Analysis }\end{array}$ & $\begin{array}{c}\text { Physical } \\
\text { Structure }\end{array}$ \\
\hline Over Production & 0.00 & 0.00 & 0.00 & 0.00 & 0.00 & 0.00 & 0.00 \\
\hline Waiting & 29.00 & 29.00 & 3.22 & 0.00 & 9.67 & 9.67 & 0.00 \\
\hline Transportation & 69.00 & 0.00 & 0.00 & 0.00 & 0.00 & 0.00 & 7.67 \\
\hline Inventory & 5.00 & 0.00 & 1.67 & 0.56 & 0.00 & 0.56 & 0.00 \\
\hline Motion & 7.67 & 23.00 & 7.67 & 0.00 & 23.00 & 7.67 & 2.56 \\
\hline Defect & 0.00 & 0.00 & 0.00 & 0.00 & 0.00 & 0.00 & 0.00 \\
\hline Over Process & 0.00 & 0.00 & 0.00 & 0.00 & 0.00 & 0.00 & 0.00 \\
\hline Total & 110.67 & 52.00 & 12.56 & 0.56 & 32.67 & 17.89 & 10.22 \\
\hline
\end{tabular}

Dari hasil perhitungan tabel diatas diketahui bahwa tool yang tepat untuk melakukan penelitian adalah Process Activity Mapping karena memiliki nilai tertinggi yaitu 110.67.

\section{Big Picture Mapping (Current State Mapping)}

Big Picture Mapping menggambarkan peta aliran material dan informasi dimulai dari saat material masuk ke proses sampai dengan menjadi produk jadi. Data tersebut didapat dari hasil wawancara dan observasi langsung. 


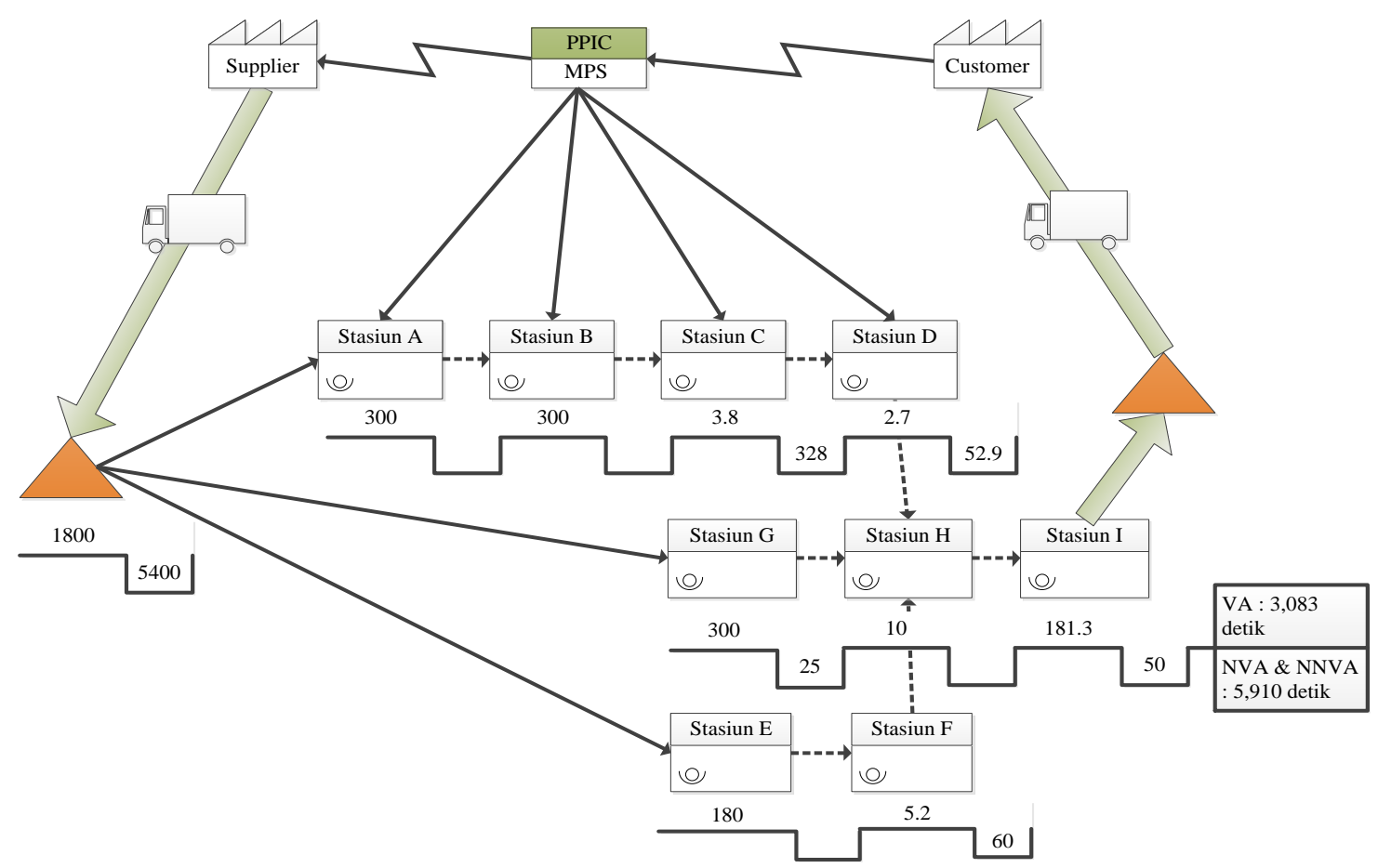

Gambar 2. Current State Mapping

Dari data current state mapping diketahui informasi sebagai berikut :

1. Departemen PPIC menerima forecast dari customer. Kemudian dari forecast tersebut mereka membuat MPS (Master Production Schedule) sebagai dasar untuk membuat PO (Purchase Order) dan dikirimkan kepada supplier untuk membeli bahan baku. MPS tersebut juga dikirimkan kepada bagian produksi sebagai dasar untuk jadwal produksi.

2. Supplier mengirim bahan baku dan masuk ke gudang bahan baku. Pengambilan bahan baku membutuhkan waktu sebesar 5400 detik dan sebesar 1800 detik untuk menaruh material disetiap stasiun kerja.

3. Untuk proses produksi perakitan IV Cath terdiri dari 9 stasiun kerja dan membutuhkan waktu total sebesar 8,996 detik.

4. Total waktu VA (Value Added) dari keseluruhan proses adalah sebesar 3,083 detik dan total waktu NVA (Non Value Added) \& NNVA (Necessary but Non Value Added) adalah sebesar 5,910 detik.

5. Setelah produk selesai maka produk akan disimpan pada gudang finish good sebelum dikirim ke customer.

\section{Process Activity Mapping (PAM) Current State}

Process Activity Mapping (PAM) merupakan pendekatan teknis yang digunakan dalam aktivitas di lantai produksi, tool ini memetakan seluruh proses secara detail di setiap tahapannya. Process activity mapping mengkategorikan setiap tahapan ke dalam beberapa jenis aktivitas seperti value ading activities, non value adding activities, serta necessary non value adding activities. Tool ini juga bisa mengidentifikasi lead time baik itu aliran fisik maupun yang berupa informasi dilingkungan perusahaan dan diseluruh area supply chain. (Hines and Rich, 1997. The Seven Value Stream Mapping Tools) 
Tabel 6. Tabulasi Ringkasan Perhitungan dan Persentase dari PAM current state (Sumber : Hasil Perhitungan)

\begin{tabular}{|c|c|c|c|c|c|c|c|}
\hline Kategori & 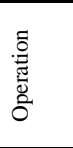 & 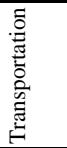 & 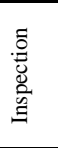 & 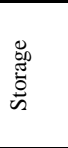 & $\frac{\vec{I}}{\stackrel{D}{0}}$ & 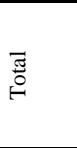 & 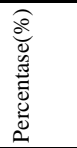 \\
\hline \multicolumn{8}{|c|}{ Jumlah Aktivitas } \\
\hline VA & 29 & 0 & 2 & 1 & 0 & 32 & $78.0 \%$ \\
\hline NVA & 1 & 0 & 0 & 0 & 0 & 1 & $2.4 \%$ \\
\hline NNVA & 1 & 7 & 0 & 0 & 0 & 8 & $19.5 \%$ \\
\hline Total & 31 & 7 & 2 & 1 & 0 & 41 & $100 \%$ \\
\hline \multicolumn{8}{|l|}{ Jumlah Waktu } \\
\hline VA & 2,901 & - & 2 & 180 & - & 3,083 & $34.27 \%$ \\
\hline NVA & 3 & - & - & - & - & 3 & $0.03 \%$ \\
\hline NNVA & 300 & 5,610 & - & - & - & 5,910 & $65.70 \%$ \\
\hline Total & 2,598 & 5,610 & 1.8 & 180 & 0 & 8,996 & $100.0 \%$ \\
\hline
\end{tabular}

Dari hasil PAM diketahui bahwa terdapat persentase aktivitas value added (VA) sebesar $34.27 \%$, non value added (NVA) sebesar $0.03 \%$ dan necessary but non value added (NNVA) sebesar $65.70 \%$. Berdasarkan hasil persentase diatas dapat dilihat bahwa aktivitas NVA didapat dari aktivitas operation dan aktivitas NNVA didapat dari aktivitas transportation.

\section{Identifikasi Penyebab Masalah Dan Tindakan Perbaikan}

Dari data analisa PAM, selanjutnya dilakukan analisa penyebab terjadinya pemborosan pada proses perakitan IV Cath. Adapun analisa penyebab masalah adalah sebagai berikut :

Tabel 7. Analisa Penyebab Waste (Sumber : Hasil Analisa)

\begin{tabular}{|c|c|c|}
\hline Stasiun Kerja & Waste & Penjelasan \\
\hline $\begin{array}{l}\text { Pengambilan } \\
\text { material ke } \\
\text { gudang }\end{array}$ & $\begin{array}{c}\text { NNVA } \\
\text { (Transportation) }\end{array}$ & $\begin{array}{l}\text { Pengambilan material masih manual menggunakan trolley } \\
\text { kecil sehingga pengambilan tidak maksimal. Waktu yang } \\
\text { dibutuhkan sebesar } 3,600 \text { detik untuk jarak } 30 \text { meter. }\end{array}$ \\
\hline \multirow[t]{2}{*}{$\mathrm{C}$} & $\begin{array}{l}\text { NNVA } \\
\text { (Motion) }\end{array}$ & \begin{tabular}{|l} 
- Mengambil material \\
Dari hasil analisa, permasalahan bukan dari waktu \\
pengambilan tetapidari seringnya operator mengambil material \\
dikarenakan tempat untuk menaruh material yang kecil \\
sehingga material akan cepat habis dan operator akan sering \\
mengambil material. Total waktu untuk pengambilan material \\
dalam satu shift adalah sebesar 2,400 detik.
\end{tabular} \\
\hline & $\begin{array}{c}\text { NNVA } \\
\text { (Transportation) }\end{array}$ & \begin{tabular}{|l|} 
- Mengrim material ke proses selanjutnya \\
Dari hasil analisa, didapatkan jarak antara stasiun C dan \\
stasiun D sejauh 2 meter sehingga memerlukan waktu \\
sebanyak 25 detik.
\end{tabular} \\
\hline \multirow{3}{*}{ D } & \multirow[b]{2}{*}{ NVA (waiting) } & - Waiting mesin bekerja \\
\hline & & $\begin{array}{l}\text { Pada stasiun D didapati bahwa ada aktivitas operator } \\
\text { menunggu selama mesin bekerja. Waktu menunggu sebesar } \\
3.2 \text { detik dalam satu siklus proses. }\end{array}$ \\
\hline & $\begin{array}{c}\text { NNVA } \\
\text { (transportation) }\end{array}$ & $\begin{array}{l}\text { - Mengirim material ke proses selanjutnya } \\
\text { Dari hasil analisa, didapatkan jarak antara stasiun D dan } \\
\text { stasiun } \mathrm{H} \text { sejauh } 4 \text { meter sehingga memerlukan waktu } \\
\text { sebanyak } 50 \text { detik. }\end{array}$ \\
\hline $\mathrm{F}$ & $\begin{array}{c}\text { NNVA } \\
\text { (transportation) }\end{array}$ & $\begin{array}{l}\text { - Mengirim material ke proses selanjutnya } \\
\text { Dari hasil analisa, didapatkan jarak antara stasiun } \mathrm{F} \text { dan } \\
\text { stasiun } \mathrm{H} \text { sejauh } 5 \text { meter sehingga memerlukan waktu } \\
\text { sebanyak } 60 \text { detik. }\end{array}$ \\
\hline I & $\begin{array}{c}\text { NNVA } \\
\text { (transportation) }\end{array}$ & \begin{tabular}{|l|} 
- Mengambil Material \\
Operator harus mengambil material ke stasiun $\mathrm{H}$ sejauh 3 \\
meter selama 50 detik.
\end{tabular} \\
\hline
\end{tabular}


Dari hasil analisa penyebab masalah kemudian dilakukan tindakan perbaikan untuk memghilangkan atau mengurangi pemborosan/waste. Detail perbaikan dijelaskan pada tabel 8.

Tabel 8. Data Perbaikan (Sumber : Hasil Analisa)

\begin{tabular}{|c|c|c|}
\hline Stasiun Kerja & Sebelum Perbaikan & Setelah Perbaikan \\
\hline \begin{tabular}{|l|} 
Pengambilan \\
Material ke Gudang
\end{tabular} & $\begin{array}{l}\text { Menggunakan trolley kecil sehingga } \\
\text { pengambilan tidak maksimal dan } \\
\text { membutuhkan waktu 3,600 detik }\end{array}$ & $\begin{array}{|lrr|}\text { Menggunakan } & \text { handlift } & \text { sehingga } \\
\text { pengambilan } & \text { material } & \text { dapat } \\
\text { dimaksimalkan. } & \text { Waktu yang } & \text { dibutuhkan } \\
\text { menurun menjadi } & 1,800 \text { detik. } & \\
\end{array}$ \\
\hline $\begin{array}{c}\text { Stasiun Kerja C } \\
\text { NNVA (Motion) } \\
\text { Pengambilan } \\
\text { Material } \\
\end{array}$ & \begin{tabular}{|l|} 
Tempat material kecil. Kapasitas \\
penyimpanan material hanya sebesar \\
500 pcs
\end{tabular} & $\begin{array}{l}\text { Mengganti tempat material dengan yang } \\
\text { lebih besar. Kapasitas menjadi } 1500 \text { pcs. }\end{array}$ \\
\hline $\begin{array}{l}\text { Stasiun Kerja C } \\
\text { NNVA } \\
\text { (Transportation) } \\
\text { Mengirim material }\end{array}$ & $\begin{array}{l}\text { Mengirim material dari proses } \mathrm{C} \text { ke } \\
\text { proses D dengan berjalan kaki } \\
\text { (manual). }\end{array}$ & $\begin{array}{l}\text { Membuat conveyor untuk pengiriman } \\
\text { produk antar stasiun kerja. Mengurangi } \\
\text { waktu transportation menjadi } 3 \text { detik. }\end{array}$ \\
\hline $\begin{array}{c}\text { Stasiun Kerja D } \\
\text { NVA } \\
\text { (Waiting) } \\
\text { Menunggu Mesin }\end{array}$ & $\begin{array}{l}\text { Satu mesin dan satu operator. } \\
\text { Terdapat aktivitas NVA yaitu } \\
\text { operator menunggu mesin bekerja. }\end{array}$ & $\begin{array}{l}\text { Menggabungkan mesin dari dua mesin dan } \\
\text { dua operator menjadi dua mesin dan satu } \\
\text { operator. Mengurangi waktu tunggu } \\
\text { sebesar } 3.2 \text { detik. }\end{array}$ \\
\hline \begin{tabular}{|c|} 
Stasiun Kerja D \\
NNVA \\
(Transportation) \\
Mengirim material \\
\end{tabular} & $\begin{array}{l}\text { Mengirim material dari proses } \mathrm{D} \text { ke } \\
\text { proses } \mathrm{H} \text { dengan berjalan kaki } \\
\text { (manual) }\end{array}$ & $\begin{array}{l}\text { Membuat conveyor untuk pengiriman } \\
\text { produk antar stasiun kerja. Mengurangi } \\
\text { waktu transportation menjadi } 3 \text { detik. }\end{array}$ \\
\hline $\begin{array}{c}\text { Stasiun Kerja F } \\
\text { NNVA } \\
\text { (Transportation) } \\
\text { Mengirim material }\end{array}$ & $\begin{array}{l}\text { Mengirim material dari proses } \mathrm{F} \text { ke } \\
\text { proses } \mathrm{H} \text { dengan berjalan kaki } \\
\text { (manual) }\end{array}$ & $\begin{array}{l}\text { Membuat conveyor untuk pengiriman } \\
\text { produk antar stasiun kerja Mengurangi } \\
\text { waktu transportation menjadi } 3 \text { detik. }\end{array}$ \\
\hline $\begin{array}{l}\text { Stasiun Kerja I } \\
\text { NNVA } \\
\text { (transportation) }\end{array}$ & $\begin{array}{l}\text { Mengambil material dari proses } \mathrm{H} \\
\text { sejauh } 3 \text { meter dengan berjalan kaki } \\
\text { (manual) }\end{array}$ & $\begin{array}{l}\text { Memindahkan meja inspeksi dekat dengan } \\
\text { proses H. Jarak berkurang menjadi } 1 \\
\text { meter. }\end{array}$ \\
\hline
\end{tabular}

\section{Future State Mapping}

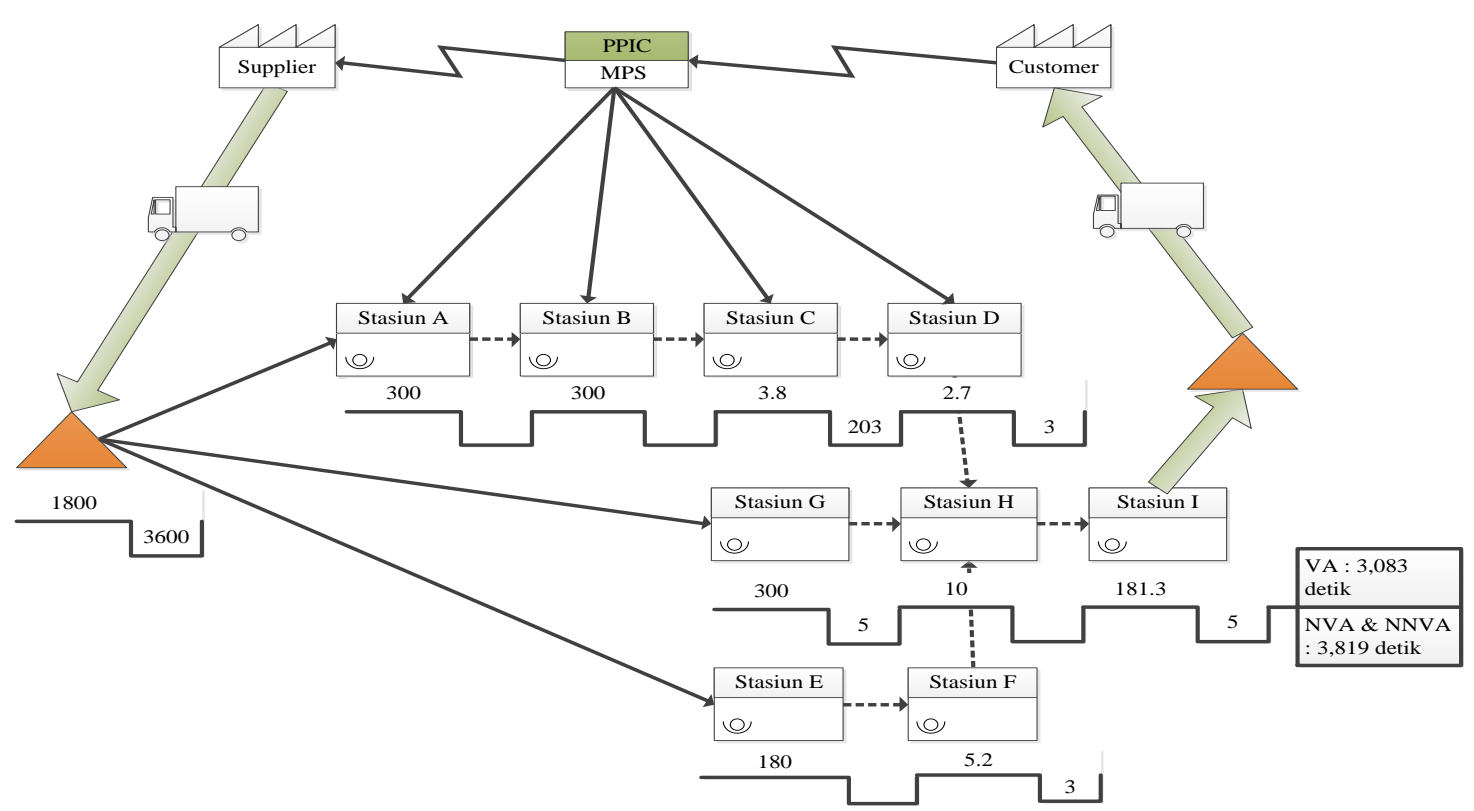

Gambar 3. Future State Mapping 
Setelah dilakukan perbaikan, digambarkan future state mapping dengan perubahan yaitu berkurangnya waktu proses dari 8,992 detik menjadi 6,902 detik. Total waktu VA (Value Added) dari keseluruhan proses tetap yaitu sebesar 3,083 detik dan total waktu NVA (Non Value Added) \& NNVA (Necessary but Non Value Added) menurun menjadi 3,819 detik.

\section{Process Activity Mapping (PAM) Future State}

Process Activity Mapping future state menggambarkan aliran material dan aktifitas setelah dilakukan perbaikan.

Tabel 8. Tabulasi Ringkasan Perhitungan dan Persentase dari PAM future state

\begin{tabular}{|c|c|c|c|c|c|c|c|}
\hline Kategori & 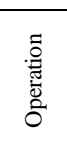 & 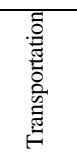 & 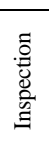 & 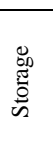 & $\frac{\text { 吾 }}{\text { ఏ }}$ & 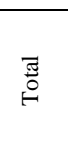 & 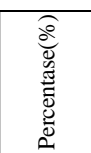 \\
\hline \multicolumn{8}{|c|}{ Jumlah Aktivitas } \\
\hline VA & 29 & 0 & 2 & 1 & 0 & 32 & $80.00 \%$ \\
\hline NVA & 0 & 0 & 0 & 0 & 0 & 0 & $0.00 \%$ \\
\hline NNVA & 1 & 7 & 0 & 0 & 0 & 8 & $20.00 \%$ \\
\hline Total & 30 & 7 & 2 & 1 & 0 & 40 & $100 \%$ \\
\hline \multicolumn{8}{|c|}{ Jumlah Waktu } \\
\hline VA & 2,901 & - & 2 & 180 & - & 3,083 & $44.67 \%$ \\
\hline NVA & - & - & - & - & - & - & $0.00 \%$ \\
\hline NNVA & 200 & 3,619 & - & - & - & 3,819 & $55.33 \%$ \\
\hline Total & 2,701 & 3,619 & 1.8 & 180 & 0 & 6,902 & $100.00 \%$ \\
\hline
\end{tabular}

Dari data tabel diatas, diketahui menurunnya aktivitas dari 41 menjadi 40 aktivitas. Waktu VA naik dari $34.2 \%$ menjadi $44.7 \%$, waktu NVA dapat direduksi menjadi $0 \%$ dan waktu NNVA menurun dari $65.7 \%$ menjadi $55.33 \%$.

\section{Perhitungan Output Produksi Setelah Perbaikan}

Setelah dilakukan perbaikan, peneliti melakukan pengumpulan data output produksi dari bulan Agustus 2017 - Oktober 2017 sebagai berikut :

Tabel 9. Data Perhitungan Output Setelah Perbaikan (Sumber : PT. NIJ)

\begin{tabular}{|l|c|c|}
\hline \multirow{2}{*}{\multicolumn{1}{|c|}{ Bulan }} & Output Produksi & Target Output \\
\cline { 2 - 3 } & (pcs) & (pcs) \\
\hline Agustus 2017 & 311,000 & 310,000 \\
\hline September 2017 & 328,000 & 320,000 \\
\hline Oktober 2017 & 325,000 & 320,000 \\
\hline Rata-Rata & 321,333 & 316,666 \\
\hline
\end{tabular}

Dari data diatas diketahui setelah dilakukan perbaikan terjadi peningkatan output produksi menjadi sebesar 321,333 pcs/bulan. 


\section{KESIMPULAN DAN SARAN}

A. KESIMPULAN

Berdasarkan hasil penelitian dan pembahasan yang telah di lakukan terhadap proses pengolahan data produksi produk Intra Venous Catheter (IV Cath) dengan menggunakan metode lean manufacturing, maka dapat ditarik suatu kesimpulan yaitu, sebagai berikut :

1. Jenis waste yang diketahui adalah transportation (54.8\%). waiting (23.0\%), motion (18.3\%) dan inventory (4.0\%).

2. Dari hasil perhitungan pemilihan value stream analysis tool yang akan digunakan diketahui bahwa process activity mapping memiliki nilai tertinggi yaitu 110.67 . Sehingga process activity mapping yang akan digunakan sebagai tool untuk menganalisa waste.

3. Solusi perbaikan untuk menghilangkan waste adalah untuk waste transportation dengan membuat conveyor untuk mengurangi waktu pengiriman material dari satu proses ke proses selanjutnya, dengan memindahkan meja inspeksi supaya dekat dengan stasiun kerja $\mathrm{H}$. Untuk waste motion dengan mengganti tempat material dengan ukuran lebih besar. Untuk waste waiting dengan menggabungkan dua proses dengan dua operator menjadi dua proses dengan satu operator. Waktu lead time sebelum perbaikan adalah sebesar 8,996 detik dan setelah perbaikan menjadi 6,902 detik.

4. Rata-rata output produksi sebelum dilakukan perbaikan adalah 292,768 pcs sedangkan setelah perbaikan rata-rata output produksi adalah sebesar 321,333 pcs sehingga terjadi kenaikan sebesar $10 \%$.

\section{B. SARAN}

Dari hasil penelitian dapat diberikan beberapa saran dan bias menjadi masukan bagi perusahaan sebagai berikut :

1. Perusahaan sebaiknya melakukan training mengenai lean manufacturing kepada seluruh tim manajemen agar pemahaman mengenai konsep lean dapat diterapkan disemua lini perusahaan tidak hanya diproduksi saja.

2. Manajemen diharapkan rutin melakukan genba untuk mengetahui permasalahan yang ada baik didepartemen produksi maupun didepartemen lainnya.

3. Perusahaan diharapkan tetap melaksanakan sistem 5R (Ringkas, Rapi, Resik, Rawat dan Rajin) yang baik disemua departemen agar tercipta lingkungan kerja yang nyaman, efektif \& efisien.

4. Pada penelitian selanjutnya dapat dilakukan perkembangan penelitian untuk kontrol inventori.

\section{DAFTAR PUSTAKA}

[1] Gasperz, Vincent. 2012. All In One Management Toolbook. Tri Al Bros Publishing.

[2] Irma Rahma Irawan .2017. Peningkatan Efisiensi Proses Produksi The Celup Single Chamber Menggunakan Pendekatan Lean Manufacturing Di PT XYZ. Banten.

[3] Liker, J. K., The Toyota Way, Erlangga, Jakarta, 2005.

[4] Rother, Mike and Shook, John. 2009. Learning to See. Lean Enterprise Institute.

[5] Vincent Gaspersz Avanti Fontana. 2011 . Lean Six Sigma for Manufacturing and service Industries. Baranangsiang Indah Bogor : Vinchrisco Publication.

[6] Wantah, M., Astra Management System, Trio Jaya, Bogor. 